\title{
Influência de Polimorfismos Genéticos sobre os Parâmetros da Curva de Crescimento em Bovinos de Corte ${ }^{1}$
}

\author{
Claudia Cristina Paro de Paz ${ }^{2}$, Irineu Umberto Packer ${ }^{3}$, Alfredo Ribeiro de Freitas ${ }^{4}$, Daniela \\ Tambasco-Talhari ${ }^{5}$, Luciana Correa de Almeida Regitano ${ }^{4}$, Maurício Mello de Alencar ${ }^{4}$, Armando \\ de Andrade Rodrigues ${ }^{4}$
}

\begin{abstract}
RESUMO - Registros de pesos ao nascimento, ao desmame e mensais dos 8 aos 19 meses de idade, referentes à animais dos grupos genéticos: 1/2Canchim-Nelore (CN), 1/2Angus-Nelore (AN) e 1/2Simental-Nelore (SN), pertencentes à Embrapa Pecuária Sudeste, São Carlos, SP, foram analisados pela técnica de modelos não-lineares incluindo, no modelo Logístico, os efeitos fixos de grupo de contemporâneos e das classes de genótipos dos genes da kappa-caseína-HinfI (CSN3): AA e AB, do hormônio do crescimento-AluI (GH): LL e LV e da $\beta$-lactoglobulina-HaeIII (LGB): AA, AB e BB, com o objetivo de verificar a influência destes genes sobre a curva de crescimento desses animais. Os resultados sugerem que os parâmetros $A$ e $k$ da função Logística utilizada para descrever o crescimento dos grupos genéticos CN, AN e SN, foram influenciados pelos polimorfismos dos genes CSN3, GH e LGB. As maiores diferenças entre os genótipos para os genes CSN3, GH e LGB foram observadas a partir dos 12-13 meses de idade. O genótipo AA para CSN3 apresentou maior taxa de maturação $(k)$ que o genótipo AB nos grupos genéticos CN, AN e SN. Quanto ao valor assintótico $(A)$, a diferença entre AA e AB foi pequena nos grupos genéticos CN e SN. Para o polimorfismo do GH no grupo genético AN, o genótipo LL apresentou valores de $A$ e $k$ inferiores em relação ao $L V$, enquanto no grupo genético SN os animais do genótipo LV apresentaram menor valor de $A$ e maior de $k$ em relação ao LL. O mesmo ocorreu para o LGB, em que os genótipos AA e AB apresentaram estimativas do parâmetro $k$ superiores em relação ao genótipo BB no grupo genético AN, enquanto o genótipo AB apresentou estimativa de $k$ inferior em relação ao genótipo $\mathrm{BB}$, no grupo genético SN.
\end{abstract}

Palavras-chave: bovinos cruzados, genes candidatos, marcadores genéticos, modelo Logístico

\section{Effect of Genetic Polymorphisms on the Growth Curve Parameters in Beef Cattle}

\begin{abstract}
Records of the weights at birth, weaning and monthly from 8 to 19 months of age from three genetic groups: $1 / 2$ CanchimNellore (CN), 1/2Angus-Nellore (AN) e 1/2Simmental-Nellore (SN), born in 1998 and 1999 in Southeast Brazil, were used to fit a Logistic nonlinear model that included the fixed effects of the contemporary group and genotype of the genes kappa-casein-HinfI (CSN3): AA and $\mathrm{AB}$, growth hormone-AluI (GH): LL and LV, and $\beta$-lactoglobulin-HaeIII (LGB): AA, AB and BB, to examine the effect of these markers on the growth curve. The Logistic model used to explain the growth of the CN, AN and SN genetic groups, was influenced by the genotypes of the CSN3, GH e LGB markers. The major differences started at 12-13 months of age. The value of the maturing rate ( $k$ ) of the AA genotype for CSN3 was superior in relation to AB genotype in the CN, AN and SN genetic groups. However, there was observed small difference in estimate of the asymptotic value $(A)$ for the AA and AB genotypes in CN and SN genetic groups. For the $\mathrm{GH}$ polymorphism there were inferior values of the parameters $A$ and $k$ to LL genotype in relation to LV genotype for the AN genetic group, however for the SN genetic group there was inferior value of the parameter $A$ and superior value of the parameter $k$ to $L V$ genotype in relation to LL genotype. The same was observed for the LGB, there were superior values of the parameter $k$ of the AA and AB genotypes in relation to the $\mathrm{BB}$ for the $\mathrm{AN}$ genetic group, however, there was inferior value of the parameter $k$ of the AB genotype in relation to the $\mathrm{BB}$, for the $\mathrm{SN}$ genetic group.
\end{abstract}

Key Words: crossbred, candidate genes, genetic marker, Logistic model

\section{Introdução}

Os marcadores moleculares constituem ferramenta importante para a identificação de animais portadores de doenças genéticas, determinação de parentesco e associação com características de interesse econômico. Características de produção, particularmente por sua importância, têm propiciado vários estudos com a finalidade de gerar metodologias que permitam maior acurácia na avaliação e seleção de animais.

\footnotetext{
${ }^{1}$ Parte da tese de Doutorado do primeiro autor, apresentada à ESALQ/ USP - Piracicaba - SP, financiada pelo CNPq e pela FAPESP ${ }^{2}$ Pesquisador Científico do Instituto de Zootecnia e Bolsista de Doutorado do CNPq, ESALQ/USP (ccppaz@aptaregional.sp.gov.br)

${ }^{3}$ Professor do Departamento de Zootecnia da Escola Superior de Agricultura "Luiz de Queiroz", ESALQ/USP, Piracicaba, SP (iupacker@esalq.usp.br).

4 PesquisadorEmbrapaPecuária Sudeste, São Carlos-SP (ribeiro@cppse.embrapa.br; luciana@cppse.embrapa.br; mauricio@cppse.embrapa.br).

${ }^{5}$ Bolsista de Doutorado da FAPESP, Universidade Federal de São Carlos - SP.
} 
Genes candidatos para determinada característica são seqüências de genes de ação biológica conhecida que estão envolvidas no desenvolvimento ou nos processos fisiológicos responsáveis pela expressão da característica. Os polimorfismos da kappa-caseínaHinfI (CSN3) do hormônio do crescimento-AluI (GH) e da $\beta$-lactoglobulina-HaeIII (LGB) são considerados genes candidatos e têm sido utilizados com o propósito de associá-los às características de produção.

Estruturalmente o gene do hormônio do crescimento bovino (GH), apresenta alto grau de polimorfismo, com vários sítios polimórficos (Lucy et al., 1991; Kirkpatrik, 1992; Zhang et al., 1993). Este gene exerce importantes funções biológicas na regulação do crescimento animal (Gluckman et al., 1987) e nos processos envolvidos na resistência a doenças (Arkins et al., 1993). Os polimorfismos do GH foram associados à produção (Hoj et al., 1993, Moody et al., 1996) e quantidade de gordura do leite (Yao et al., 1996), ao peso ao nascimento (Rocha et al., 1992) e também à composição e qualidade da carne (Taylor et al., 1998).

A kappa-caseína descrita por Medrano \& AguilarCordova (1990a) e a $\beta$-lactoglobulina, descrita por Medrano \& Aguilar-Cordova (1990b), são proteínas presentes no leite e em princípio foram associadas às características de produção de leite (Ng-Kwai-Hang et al., 1984; Ron et al., 1994). A kappa-caseína faz parte do grupo estrutural das caseínas, que são as únicas proteínas passíveis de coagulação no leite e está relacionada com o rendimento e a qualidade do queijo (Lin et al., 1992). A $\beta$-lactoglobulina faz parte da fração globulina das proteínas do soro do leite e é considerada como importante fonte de imunidade para os organismos. Essas duas proteínas apresentaram importante relação entre si (Hines et al., 1981; Bovenhuis et al., 1992). A $\beta$-lactoglobulina parece ainda estar associada às porcentagens de gordura e de kappa-caseína presentes no leite (Lin et al., 1992).

Com relação às características de crescimento, os genes que codificam estas proteínas (kappa-caseína e $\beta$-lactoglobulina) foram, de acordo com Moody et al. (1996), associados aos valores genéticos para o peso ao nascimento, ganho de peso do nascimento ao desmame, ganho de peso do desmame a um ano de idade, e ainda, para o valor genético materno para peso ao nascimento e para ganho de peso do nascimento ao desmame. Associações importantes também foram identificadas por Lin et al. (1987) com o peso ao nascimento, peso aos 350 dias de idade e com peso ao primeiro parto.

Análises prévias (Paz, 2002), em que os parâmetros $A$ e $k$ foram analisados pela técnica de modelos lineares usando o PROC GLM (SAS, 2001), detectaram efeitos significativos $(\mathrm{P}<0,01$ e $\mathrm{P}<0,05)$ dos polimorfismos dos genes CSN3, GH e LGB, respectivamente, sobre os parâmetros $A$ e $k$ da curva Logística ajustada ao conjunto de dados de peso em função da idade, de animais do grupo genético $1 / 2$ Canchim-Nelore. Entretanto, análises que consideram os parâmetros das funções não-lineares e os efeitos fixos e/ou covariáveis simultaneamente no modelo parecem ser mais adequadas. Schabenberger (2001) apresentou um exemplo de análise de variância usando um modelo não-linear Log-Logístico, com quatro parâmetros a serem estimados e y (variável resposta) em função da taxa de crescimento (kg/ha), com dois tratamentos. Nessa análise, as estimativas dos parâmetros do modelo Log-Logístico foram obtidas por um modelo que incluiu o efeito dos tratamentos, de maneira que a influência desse efeito sobre os parâmetros da função Log-Logística também foi considerada.

No presente trabalho, a modelagem dos dados de peso em função da idade, de animais dos grupos genéticos 1/2Canchim-Nelore, 1/2Angus-Nelore e $1 / 2$ Simental-Nelore, foi realizada pela técnica de modelos não lineares usando-se o procedimento NLIN (SAS, 2001). O modelo não-linear Logístico incluiu os efeitos fixos de grupo de contemporâneos e dos genótipos dos genes da kappa-caseína-HinfI (CSN3): AA e AB do hormônio do crescimento-AluI (GH): LL e LV e da $\beta$-lactoglobulina-HaeIII (LGB): AA, AB e $B B$, com o objetivo de verificar a influência destes genes sobre a curva de crescimento dos animais e estimar os parâmetros da função Logística, simultaneamente.

\section{Material e Métodos}

Foram utilizadas informações de 230 animais dos grupos genéticos $1 / 2$ Canchim-Nelore $(n=83), 1 / 2$ AngusNelore $(n=76) e^{1 / 2}$ Simental-Nelore $(n=71)$, pertencentes à Embrapa Pecuária Sudeste, São Carlos, SP.

Anualmente, foram usados 2, 5 e 4 touros das raças Canchim, Anguse Simental, respectivamente, acasalados com 57, 57 e 53 fêmeas Nelore. Os cruzamentos foram feitos em dois ciclos (anos de 1998 e 1999).

Na edição dos dados, as variáveis fenotípicas

R. Bras. Zootec., v.33, n.4, p.858-869, 2004 
foram obtidas do arquivo que continha a identificação do animal, touro e vaca, os pesos ao nascimento, ao desmame (7 meses de idade em média), e mensalmente (dos 8 aos 19 meses de idade), além de sexo, dia, mês e ano de nascimento do animal (1998 ou 1999) e da vaca, manejo alimentar $(\mathbf{C S}=$ com suplementação ou SS = sem suplementação) e grupo genético (CN= 1/2Canchim-Nelore, AN= 1/2Angus-Nelore e $\mathbf{S N}=1 / 2$ Simental-Nelore). Outro arquivo continha a identificação dos animais e as variáveis genotípicas que compreendiam os polimorfismos de restrição dos genes da kappa-caseína-HinfI (Barendse et al., 1997), do hormônio do crescimento-AluI (Lucy et al., 1991), e $\beta$-lactoglobulina-HaeIII (Barendse et al. 1997), que são do tipo RFLP-PCR e estão distribuídos nos cromossomos 6, 19 e 11 de bovinos, às distâncias de 103 cM, 72,7 cM e 150 cM, respectivamente, cujas classes genotípicas observadas foram LL e LV para o GH e AA, AB e BB para CSN3 e LGB.

A partir das informações do primeiro arquivo, foram formados oito grupos de contemporâneos pela concatenação das variáveis sexo, ano de nascimento e grupo de manejo alimentar.

Durante a edição dos dados, foram eliminadas as observações dos animais que pertenciam à classe de polimorfismos genéticos (para os genes CSN3, GH e LGB) desconhecida, ou com menos de cinco animais e à classe de grupo de manejo alimentar desconhecido, além de eliminar os genótipos BB do gene CSN3 dos animais $\mathrm{CN}$ e $\mathrm{AN}$ e AA do gene LGB dos animais SN. Dessa forma, restaram 66, 68 e 52 informações, respectivamente, para os grupos genéticos $\mathrm{CN}$, AN e SN do total de 230 animais.

\section{Freqüências alélica e genotípica}

Na Tabela 1, estão apresentadas as freqüências genotípica e alélica dos polimorfismos dos genes candidatos CSN3, GH e LGB dos animais cruzados $\mathrm{CN}, \mathrm{AN}$ e SN.

Os polimorfismos identificados para kappacaseína-HinfI, hormônio do crescimento-AluI e $\beta$ lactoglobulina-HaeIII apresentaram dois alelos conforme descritos por Lucy et al. (1991), Medrano \& Aguilar-Cordova (1990a) e Medrano \& AguilarCordova (1990b), respectivamente.

\section{Análises estatísticas}

O conjunto de dados de peso em função da idade foi ajustado pelo modelo Logístico (Nelder, 1961). As estimativas dos parâmetros dos modelos Logísticos ajustados para os grupos genéticos foram descritas por
Paz (2002). A estimação dos parâmetros de cada modelo foi realizada por meio da técnica de modelos não-lineares usando o procedimento NLIN (SAS, 2001) e o método de Gauss Newton modificado.

O modelo Logístico é representado pela seguinte equação:

$$
\mathrm{y}_{\mathrm{t}}=\mathrm{A}\left(1+\mathrm{be} \mathrm{e}^{-\mathrm{kt}}\right)^{-\mathrm{m}}+\varepsilon
$$

em que: $y_{t}$ representa o peso corporal $(\mathrm{kg})$ no tempo t, expresso em dias após o nascimento; $A$; o peso assintótico; $b$, a constante de integração, que no modelo Logístico assume o valor 1 ; $k$, a taxa de maturidade pós-natal, a qual é um indicador da velocidade com que o animal atinge o valor assintótico; $m$, a constante que define a forma da curva nos modelos e, conseqüentemente, o ponto de inflexão da curva; e $\varepsilon$, o erro aleatório.

\section{Erro de predição}

Para as curvas médias, ajustadas pelo modelo Logístico, para cada grupo genético (Paz , 2002), foi calculado o erro de predição (EP), em porcentagem (Goonewardene et al., 1981), para cada observação, como um desvio do peso estimado em relação ao peso observado (y) dividido pelo peso observado e multiplicado por 100, obtendo-se a estimativa do erro de predição médio (EPM), para cada grupo genético. O sinal apresentado por este valor designa se a função subestimou (+) ou superestimou (-) o peso observado.

\section{Comparação entre os genótipos}

No presente estudo, foi utilizada a proposta de Schabenberger (2001), considerando-se, no modelo de análise, os polimorfismos dos genes CNS3, GH e LGB e o grupo de contemporâneos (GC) como efeitos fixos.

Inicialmente, verificou-se o efeito do GC sobre a resposta ajustada pelo modelo Logístico, considerando o conjunto de dados de peso em função da idade. A influência do GC sobre a curva de crescimento foi verificada pela técnica de modelos não-lineares (SAS, 2001), considerando-se dois modelos. O primeiro, denominado Completo, considera diferentes conjuntos de estimativas de parâmetros ( $A, k$ e $m$ ) em função dos GC, para definir a resposta ajustada pelo modelo Logístico. O segundo, denominado Reduzido, considera que não existem diferenças entre os GC, então a curva de crescimento dos animais pode ser definida por um único conjunto de estimativas de parâmetros $(A, k$ e $m)$. 
Da mesma forma que na análise anterior, foi verificada a influência dos genótipos dos animais para os genes CSN3, GH e LGB sobre a curva de crescimento. Neste caso, o modelo Completo considera diferentes conjuntos de estimativas de parâmetros $(A, k$ e $m$ ) em função dos genótipos e dos GC, para definir a resposta por meio do modelo Logístico e o modelo Reduzido considera que não existem diferenças entre os genótipos, ajustando o conjunto de dados peso-idade por meio de um modelo com número reduzido de parâmetros $(A, k$ e $m$ ), definido em função dos grupos de contemporâneos. Para cada gene estudado, foi definido um modelo Completo, que incluiu apenas o efeito principal do gene.
Modelo Completo:

$$
y_{i j t}=A_{j}\left(1+e^{-k_{j} t}\right)^{-m_{j}}+\varepsilon_{i j t}
$$

Para verificar o efeito do grupo de contemporâneos sobre a curva de crescimento foi utilizado o modelo Completo que apresenta $\mathrm{n}_{1}$ x 3 parâmetros, em que $i$ identifica o animal, $j$ identifica o GC $\left(\mathrm{j}=1, \ldots, \mathrm{n}_{1}\right), \mathrm{n}_{1}$ é o número de classes existentes para o efeito do GC e 3 é o número de parâmetros do modelo Logístico utilizado ( $\mathrm{n}_{1}$ conjuntos de três parâmetros, um para cada classe de GC).

Na segunda análise, o modelo Completo apresenta $\left(\mathrm{n}_{1} \times \mathrm{n}_{2}\right) \times 3$ parâmetros, em que $j$ identifica a concatenação dos efeitos genótipo-GC $\left[\mathrm{j}=1, \ldots, \mathrm{n}_{1} \mathrm{x}\right.$

Tabela 1 - Freqüências genotípica e alélica dos polimorfismos de genes candidatos, em bovinos de três grupos genéticos

Table 1 - Genotype and allele frequencies of the candidate genes polymorphisms from the three genetic groups in beef cattle

\begin{tabular}{|c|c|c|c|c|c|c|}
\hline $\begin{array}{l}\text { Gene candidato }^{1} \\
\text { Candidate gene }^{1}\end{array}$ & $\begin{array}{l}\text { Grupo genético (\%) } \\
\text { Genetic group }\end{array}$ & $\begin{array}{r}\text { Frequ } \\
\quad G t\end{array}$ & $\begin{array}{l}\text { Ia genot } \\
\text { pe freque }\end{array}$ & $s^{2}(\%)$ & $\begin{array}{l}\text { Frequênci } \\
\text { Allele } f r\end{array}$ & $\operatorname{lica}^{3}(\%)$ \\
\hline CSN3 & 1/2Canchim-Nelore & $\begin{array}{c}\mathrm{AA} \\
(\mathrm{n}=50)\end{array}$ & $\begin{array}{c}\mathrm{AB} \\
(\mathrm{n}=18)\end{array}$ & $\begin{array}{c}\mathrm{BB} \\
(\mathrm{n}=1)\end{array}$ & $\begin{array}{c}\mathrm{A} \\
(\mathrm{n}=118)\end{array}$ & $\begin{array}{c}B \\
(n=20)\end{array}$ \\
\hline & 1/2Canchim-Nellore & 0,724 & 0,261 & 0,015 & 0,855 & 0,145 \\
\hline CSN3 & 1/2Angu-Nelore & $\begin{array}{c}\text { AA } \\
(n=41)\end{array}$ & $\begin{array}{c}\mathrm{AB} \\
(\mathrm{n}=27)\end{array}$ & $\begin{array}{c}\mathrm{BB} \\
(\mathrm{n}=2)\end{array}$ & $\begin{array}{c}\mathrm{A} \\
(\mathrm{n}=109)\end{array}$ & $\underset{(n=31}{B}$ \\
\hline & 1/2Angu-Nellore & 0,586 & 0,386 & 0,028 & 0,779 & 0,221 \\
\hline CSN3 & 1/2Simental-Nelore & $\begin{array}{c}\text { AA } \\
(n=46)\end{array}$ & $\begin{array}{c}\mathrm{AB} \\
(\mathrm{n}=10)\end{array}$ & $\begin{array}{c}\mathrm{BB} \\
(\mathrm{n}=0)\end{array}$ & $\begin{array}{c}\mathrm{A} \\
(\mathrm{n}=102)\end{array}$ & $\begin{array}{c}\mathrm{B} \\
(\mathrm{n}=10)\end{array}$ \\
\hline & $1 / 2$ Simmental-Nellore & 0,821 & 0,178 & 0 & 0,911 & 0,089 \\
\hline GH & 1/2Canchim-Nelore & $\underset{(\mathrm{n}=60)}{\mathrm{L}}$ & $\begin{array}{c}\mathrm{LV} \\
(\mathrm{n}=7)\end{array}$ & & $\begin{array}{c}\mathrm{L} \\
(\mathrm{n}=127)\end{array}$ & $\begin{array}{c}\mathrm{V} \\
(\mathrm{n}=7)\end{array}$ \\
\hline & 1/2Canchim-Nellore & 0,886 & 0,114 & 0 & 0,948 & 0,052 \\
\hline GH & 1/2Angu-Nelore) & $\underset{(\mathrm{n}=45)}{\mathrm{L}}$ & $\begin{array}{c}\mathrm{LV} \\
(\mathrm{n}=25)\end{array}$ & $\underset{(\mathrm{n}=0)}{\mathrm{W}}$ & $\begin{array}{c}\mathrm{L} \\
\mathrm{n}=(115)\end{array}$ & $\begin{array}{c}\mathrm{V} \\
(\mathrm{n}=25)\end{array}$ \\
\hline & 1/2Angu-Nellore & 0,643 & 0,357 & $\begin{array}{c}0 \\
\mathrm{~W}\end{array}$ & $\begin{array}{c}0,821 \\
\mathrm{~L}\end{array}$ & 0,179 \\
\hline $\mathrm{GH}$ & 1/2Simental-Nelore & $(n=39)$ & $(n=16)$ & $(n=0)$ & $(n=94)$ & $(n=16)$ \\
\hline & 1/2Simmental-Nellore & 0,709 & 0,291 & 0 & 0,855 & 0,145 \\
\hline LGB & 1/2Canchim-Nelore & $\begin{array}{c}\text { AA } \\
(n=6)\end{array}$ & $\begin{array}{c}\mathrm{AB} \\
(\mathrm{n}=27)\end{array}$ & $\begin{array}{c}\text { BB } \\
(\mathrm{n}=36)\end{array}$ & $\underset{(n=39)}{A}$ & $\begin{array}{c}\mathrm{B} \\
(\mathrm{n}=99)\end{array}$ \\
\hline & 1/2Canchim-Nellore & 0,087 & 0,391 & 0,522 & 0,283 & 0,717 \\
\hline & AA & $\mathrm{AB}$ & & BB & A & B \\
\hline LGB & 1⁄2Angu-Nelore & $(\mathrm{n}=12)$ & $(\mathrm{n}=31)$ & $(\mathrm{n}=28)$ & $(n=55)$ & $(\mathrm{n}=87)$ \\
\hline & 1/2Angu-Nellore & 0,169 & 0,437 & 0,394 & 0,387 & 0,613 \\
\hline & & AA & $\mathrm{AB}$ & BB & A & B \\
\hline LGB & 1/2Simental-Nelore & $(n=1)$ & $(\mathrm{n}=19)$ & $(\mathrm{n}=35)$ & $(\mathrm{n}=21)$ & $(\mathrm{n}=89)$ \\
\hline & 1/2Simmental-Nellore & 0,018 & 0,346 & 0,636 & 0,191 & 0,809 \\
\hline
\end{tabular}

${ }^{1}$ CSN3 = gene da kappa-caseína-Hinfl; GH = gene do hormônio do crescimento-Alul; LGB = gene da $\beta$-lactoglobulina-HaellI.

${ }_{1}$ CSN3 = kappa-casein-Hinfl gene; $G H$ = growth hormone-Alul gene; LGB = $\beta$-lactoglobulin-Haelll gene.

$2 \mathrm{n}=$ número de animais; ${ }^{3} \mathrm{n}=$ número total dos alelos.

${ }^{2} n=$ number of animals; ${ }^{3} n=$ number of total allele.

R. Bras. Zootec., v.33, n.4, p.858-869, 2004 
$\left.\left.\mathrm{n}_{2}\right)\right],\left(\mathrm{n}_{1} \times \mathrm{n}_{2}\right)$ é o número de classes existentes para a concatenação dos efeitos de genótipo-GC, $\mathrm{n}_{2}$ é o número de classes existentes para o efeito dos genes CSN3, GH e LGB e 3 é o número de parâmetros do modelo Logístico $\left(\mathrm{n}_{1} \times \mathrm{n}_{2}\right.$ conjuntos de três parâmetros, um para cada classe identificada pela concatenação dos efeitos de genótipo-GC).

O modelo Completo define a hipótese alternativa $\left(\mathrm{H}_{\mathrm{A}}\right)$, ou seja, que existe diferença na resposta ajustada pelo modelo Logístico entre os GC ou entre os polimorfismos genéticos de cada gene estudado, para a primeira e segunda análises.

Modelo Reduzido:

$$
\mathrm{y}_{\mathrm{it}}=\mathrm{A}\left(1+\mathrm{e}^{-\mathrm{kt}}\right)^{-\mathrm{m}}+\varepsilon_{\mathrm{it}}
$$

Utilizando-se o modelo Logístico, se não existe influência do GC sobre a curva de crescimento, então os $\mathrm{n}_{1}$ grupos de contemporâneos terão os mesmos parâmetros $A, k$ e $m$, no caso da primeira análise. Entretanto, se não existe influência do genótipo e existe efeito do GC sobre os parâmetros do modelo Logístico, então os $\left(\mathrm{n}_{1} \times \mathrm{n}_{2}\right)$ grupos definidos por genótipo-GC terão os mesmos conjuntos de estimativas de parâmetros $(A, k$ e $m)$ dos $n_{1}$ GC.

O modelo Reduzido define, como hipótese de nulidade $\left(\mathrm{H}_{\mathrm{o}}\right)$, que não há diferença na resposta ajustada pelo modelo Logístico entre os GC ou entre os polimorfismos genéticos de cada gene estudado.

Valor observado do teste $F$, utilizado para testar as diferentes hipóteses:

$$
\mathrm{F}_{\mathrm{obs}}=\frac{\left(\mathrm{SQR}_{\text {Re duzido }}-\mathrm{SQR}_{\text {Completo }}\right) /\left(\mathrm{GLR}_{\text {Re duzido }}-\mathrm{GLR}_{\text {Completo }}\right)}{\mathrm{QME} \text { Completo }}
$$

Probabilidade do valor observado de F:

$\operatorname{Prob}>\mathrm{F}=1-\operatorname{Prob}_{\mathrm{F}}\left\{\mathrm{F}_{\mathrm{obs}},\left[\mathrm{GLR}_{\text {Reduzido }}-\mathrm{GLR}_{\text {Completo }}\right],\left[\mathrm{GLR}_{\text {Completo }}\right]\right\}$

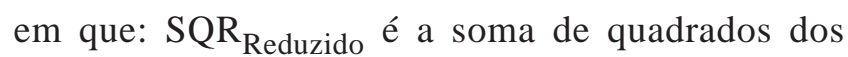
resíduos do modelo Reduzido; $\mathrm{SQR}_{\text {Completo }}$ é soma de quadrados dos resíduos do modelo Completo; $\mathrm{QME}_{\text {Completo }}$ é o quadrado médio do erro do modelo

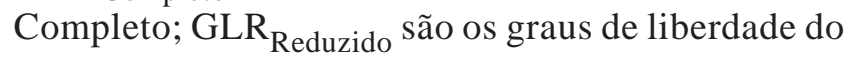
resíduo do modelo Reduzido e GLR $\mathrm{Completo}_{\text {são os }}$ graus de liberdade do resíduo do modelo Completo.

Para calcular a probabilidade do valor observado de $F$, foi usada a função PROBF (SAS, 2001), a qual retorna a probabilidade de uma distribuição $F$, com os graus de liberdade do numerador igual a $\mathrm{GLR}_{\text {Reduzido }}$ - $\mathrm{GLR}_{\text {Completo }}$ e os graus de liberdade do denominador igual a GLR Completo $_{\text {. }}$

\section{R. Bras. Zootec., v.33, n.4, p.858-869, 2004}

\section{Resultados e Discussão}

Análises estatísticas - Modelos não lineares

Erro de predição

Os erros de predição médios (EPM), em \%, e respectivos erros-padrão (\%), para animais dos grupos genéticos $1 \frac{1}{2}$ Canchim-Nelore (CN), $1 \frac{1}{2}$ Angus-Nelore (AN) e $1 \frac{1}{2}$ Simental-Nelore (SN) são apresentados na Tabela 2.

O EPM foi considerado como critério adicional para verificar a qualidade de ajuste do modelo Logístico, pelo método de Gauss-Newton modificado, aos conjuntos de dados peso-idade de animais cruzados CN, AN e SN (Paz, 2002).

Com base nesses valores médios, que apresentaram sinais negativos, constata-se que o modelo Logístico superestimou os pesos observados nos três conjuntos de dados (CN, AN e SN) em que foram realizadas as análises. A Figura 1 apresenta a distribuição dos valores de EPM, em função da idade (meses), para os animais dos três grupos genéticos. Distribuição aleatória dos valores abaixo e acima de zero indica adequado ajuste do modelo aos dados; maiores concentrações de pontos acima e abaixo de zero indicam, respectivamente, subestimação e superestimação das estimativas dos pesos, obtidas pelo modelo, com relação aos dados observados.

Na literatura, alguns trabalhos têm relatado estimativas negativas do erro de predição médio (superestimação dos valores observados) para diversos modelos não lineares ajustados aos dados peso-idade de bovinos (Goonewardene et al., 1981;

Tabela 2 - Erros de predição médios (EPM) e respectivos erros-padrão para animais de três grupos genéticos

Table 2 - Mean prediction error (MPE) and their standards error from three genetic groups of animals

\begin{tabular}{lcc}
\hline $\begin{array}{l}\text { Grupo genético } \\
\text { Genetic group }\end{array}$ & EPM(\%) & $\begin{array}{c}\text { Erro-padrão (\%) } \\
\text { Standard error (\%) }\end{array}$ \\
\hline 1/2Canchim-Nelore & $-3,0663577$ & 0,5689609 \\
$\begin{array}{l}1 / 2 \text { Canchim-Nellore } \\
\text { 1/2Angus-Nelore }\end{array}$ & $-3,4129238$ & 0,5585633 \\
1/2Angus-Nellore & & \\
1/2Simental-Nelore & $-3,8202408$ & 0,6502210 \\
1/2Simmental-Nellore & & \\
\hline
\end{tabular}


Elias, 1998). Os erros de predição médios do presente estudo (Tabela 2; Figura 1) estão de acordo com os valores de $-3,97$ e $-2,96 \%$, respectivamente, para os modelos Brody e Richards, ajustados por Elias (1998), aos conjuntos de dados peso-idade de animais Nelore, Guzerá e Gir.

Efeito dos polimorfismos genéticos sobre a curva de crescimento

O conceito de grupo de contemporâneos (GC) é de grande importância para o melhoramento animal, pois identificam os grupos de animais que realmente podem ser comparados entre si, já que é impossível fornecer uma padronização para todos os animais.

Assim, inicialmente foi testado o efeito do grupo de contemporâneos (GC) sobre a curva de crescimento dos animais CN, AN e SN. A comparação das curvas de crescimento dos animais, em função dos GC, foi realizada por meio da técnica de modelos não-lineares incluindo este efeito no modelo. Para esta análise, foram definidos dois modelos: o Completo e o Reduzido. O modelo Completo proporcionou oito conjuntos de estimativas dos parâmetros $(A, k$ e $m)$ para definir a resposta ajustada pelo modelo Logístico, um conjunto para cada GC.

O modelo Reduzido considera que não existem diferenças entre os GC, portanto o crescimento dos animais pode ser descrito por uma curva média - um único conjunto de estimativas dos parâmetros da função Logística.

A soma de quadrado e graus de liberdade do resíduo dos modelos Completo ( $\left.\mathrm{SQR}_{\text {Completo }}\right)$, $\left(\mathrm{GLR}_{\text {Completo }}\right)$ e Reduzido $\left(\mathrm{SQR}_{\text {Reduzido }}\right)$, $\left(G_{\text {Reduzido }}\right)$ e o quadrado médio do erro do modelo Completo (QME Completo ) são apresentados na Tabela 3. Estes valores são utilizados para calcular o valor observado de $F$ ( $F_{\text {obs }}$ ) e probabilidade do valor observado de $F$ (Prob $>F$ ) para distribuição. Neste caso, $\mathrm{SQR}_{\text {Completo, }} \mathrm{GLR}_{\text {Completo }}$ e $\mathrm{QME}_{\text {Completo }}$ são resultados da análise que incluiu o efeito de GC, $\mathrm{SQR}_{\text {Reduzido }}$ e GLR $\mathrm{Reduzido}_{\text {obtidos da análise que }}$ determina a curva média para cada grupo genético, usando os modelos descritos anteriormente.

De acordo com estas estatísticas, o grupo de contemporâneos influenciou $(\mathrm{P}<0,0001)$ a curva de crescimento, descrita pela função não linear Logística, dos bovinos CN, AN e SN. Estes resultados sugerem que uma única curva média (um único conjunto de parâmetro para função Logística, para cada grupo genético) não é adequada para descrever o crescimento destes animais. Assim, devem-se considerar, na descrição destas curvas, os oito conjuntos (um conjunto para cada GC) de estimativas de parâmetros $(A, k$ e $m$ ) obtidos para cada grupo genético.

A análise dos efeitos dos genes CSN3, GH e LGB sobre a curva de crescimento foram realizadas da mesma maneira que a anterior. O modelo Completo considerou $\left(\mathrm{n}_{1} \times \mathrm{n}_{2}\right)$ conjuntos de estimativas de parâmetros $(A, k$ e $m)$ formados por $\mathrm{n}_{1} \mathrm{GC}\left(\mathrm{n}_{1}=8\right)$ e
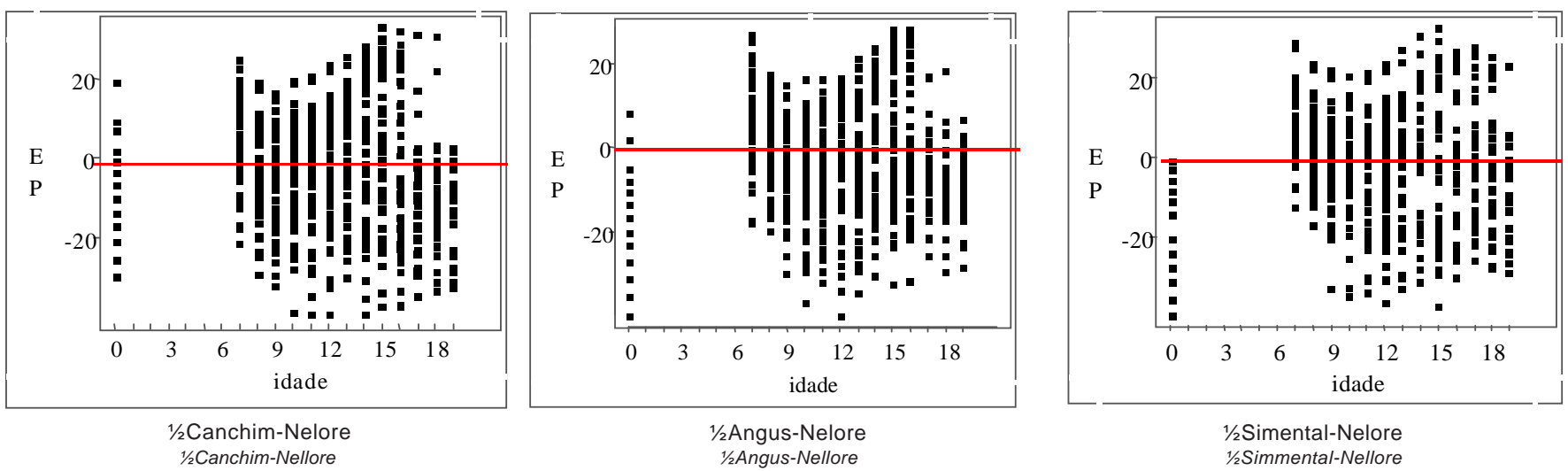

Figura 1 - Estimativas dos erros de predição médios (\%), em função da idade (meses) obtidas pelo ajuste das curvas de crescimento usando o modelo Logístico, para animais de três grupos genéticos.

Figure 1 - Mean prediction error estimates (\%), by age (months), obtained by adjusted Logistic model from three genetic groups.

R. Bras. Zootec., v.33, n.4, p.858-869, 2004 
$\mathrm{n}_{2}$ genótipos para os genes CSN3, GH e LGB. Para cada gene estudado, foi definido um modelo Completo, que incluiu apenas o efeito principal dos genes. Para os genes CSN3 e $\mathrm{GH}$, o valor de $\mathrm{n}_{2}$ foi igual a 2 (AA e AB para CSN3 e LL e LV para GH) nos três grupos genéticos (NC, NA e NS). Quanto ao gene LGB, $\mathrm{n}_{2}$ foi igual a 3 ( $\mathrm{AA}, \mathrm{AB}$ e $\mathrm{BB}$ ) para a análise dos animais NC e NA e igual a 2 (AB e BB) para os animais NS. O modelo Reduzido nesta análise, foi definido por oito conjuntos (um para cada GC) de estimativas dos parâmetros $A, k$ e $m$ da função Logística.

As distribuições dos polimorfismos dos genes CSN3, GH e LGB, para os grupos genéticos CN, AN e SN, nas classes de grupo contemporâneo, foram razoáveis (dados não apresentados), com exceção dos genes GH e LGB do grupo genético CN.

Os resultados de associação entre os polimorfismos dos genes da kappa-caseína-HinfI (CSN3), do hormônio do crescimento-AluI (GH) e da $\beta$-lactoglobulina-HaeIII (LGB) e a curva de crescimento ajustada pelo modelo Logístico para bovinos 1/2Canchim-Nelore (CN), 1/2Angus-Nelore (AN) e $1 / 2$ Simental-Nelore (SN) estão apresentados na Tabela 4.

Os genótipos do gene da kappa-caseína-HinfI (CSN3) influenciaram $(\mathrm{P}<0,001)$ a curva de crescimento dos animais dos três grupos genéticos (Tabela 4). Com exceção dos animais do grupo genético $\mathrm{CN}$, os genes do hormônio do crescimento-AluI (GH) e da $\beta$-lactoglobulina-HaeIII (LGB) também influenciaram significativamente a função Logística ajustada às curvas de crescimento desses bovinos.

O efeito de touro também influenciou $(\mathrm{P}<0,0001)$ a curva de crescimento dos animais dos grupos genéticos $\mathrm{CN}$, $\mathrm{AN}$ e $\mathrm{SN}$, quando se utilizou um modelo que incluiu os efeitos fixos de GC e touro. Esta análise foi realizada com o objetivo de verificar se os efeitos de touro e genótipos estavam confundidos. Entretanto, verificou-se que os touros estão razoavelmente bem representados nas classes dos genótipos dos genes CSN3, GH e LGB, principalmente nos grupos genéticos AN e SN.

Lin et al. (1987) e Moody et al. (1996) encontraram associações dos genes CSN3 e LGB com características de crescimento no período do nascimento aos 350 dias de idade, em bovinos de corte. Tambasco et al. (2003) utilizaram os mesmos animais envolvidos no presente estudo e encontraram efeito significativo dos polimorfismos do gene GH e da interação entre os genes GH e LGB sobre o ganho de peso do nascimento ao desmame e do desmame aos 12 meses de idade.

Os polimorfismos do GH foram associados à produção (Hoj et al., 1993), à quantidade de gordura do leite (Yao et al., 1996), ao peso no nascimento (Rocha et al., 1992), à composição e à qualidade da carcaça (Schlee et al., 1994a e1994b; Taylor et al., 1998).

Sartore \& Di Stasio (2000) sugeriram que existe associação dos genótipos de GH com peso de bezerros Piemontês. Entretanto, estudo posterior de Di Stasio et al. (2002) não revelou evidências de associação do GH com características de produção de carne nesses mesmos animais.

Na Tabela 5, estão apresentados as estimativas dos parâmetros ( $A, k$ e $m$ ), o número de animais que atingiram a convergência para cada modelo Logístico

Tabela 3 - Soma de quadrados do resíduo (SQR), graus de liberdade do resíduo (GLR), quadrado médio do erro (QME), dos modelos Completo e Reduzido, coeficiente de determinação $\left(R^{2}\right)$ do modelo Completo, valor observado de $F\left(F_{\text {obs }}\right)$ e probabilidade do valor observado de $F$ (Prob $\left.>F\right)$, para bovinos de três grupos genéticos

Table 3 - Residual sum of square (RSS), residual degrees of freedom (RDF), error mean square (EMS), of Full and Reduced models, coefficient of determination $\left(R^{2}\right)$ of Full model, observed $F$ value $\left(F_{\text {obs }}\right)$ and probability of the observed $F$ value (Pro $>$ F) of three genetic groups

\begin{tabular}{|c|c|c|c|c|c|c|c|c|}
\hline \multirow[t]{2}{*}{$\begin{array}{l}\text { Grupogenético }^{1} \\
\text { Genetic group }^{1}\end{array}$} & \multicolumn{3}{|c|}{$\begin{array}{l}\text { Modelo completo } \\
\text { Full model }\end{array}$} & \multicolumn{2}{|c|}{$\begin{array}{l}\text { Modelo reduzido } \\
\text { Reduced model }\end{array}$} & \multirow[b]{2}{*}{$\begin{array}{l}\mathrm{R}^{2}(\%) \\
R^{2}(\%)\end{array}$} & \multirow[b]{2}{*}{$\begin{array}{l}\mathrm{F}_{\text {obs }} \\
F_{\text {obs }}\end{array}$} & \multirow[b]{2}{*}{$\begin{array}{l}\text { Prob }>F \\
\text { Prob }>F\end{array}$} \\
\hline & $\begin{array}{l}\mathrm{SQR} \\
R S S\end{array}$ & $\begin{array}{l}\text { GLR } \\
R D F\end{array}$ & $\begin{array}{l}\text { QME } \\
\text { EMS }\end{array}$ & $\begin{array}{l}\text { SQR } \\
R S S\end{array}$ & $\begin{array}{l}\text { GLR } \\
R D F\end{array}$ & & & \\
\hline$\overline{\mathrm{CN}}$ & 525.468 & 760 & 691,4 & 2.008 .141 & 781 & 94,5 & 102,1 & $<0,0001$ \\
\hline AN & 495.993 & 772 & 642,5 & 1.665 .412 & 793 & 95,5 & 86,7 & $<0,0001$ \\
\hline $\mathrm{SN}$ & 384.921 & 621 & 619,8 & 1.549 .345 & 642 & 95,7 & 89,5 & $<0,0001$ \\
\hline
\end{tabular}

${ }^{1} \mathrm{CN}=1 / 2$ Canchim-Nelore; $\mathrm{AN}=1 / 2$ Angus-Nelore $; \mathrm{SN}=1 / 2$ Simental-Nelore.

${ }^{1} \mathrm{CN}=1 / 2$ Canchim-Nellore; $A N=1 / 2$ Angus-Nellore; $S N=1 / 2$ Simmental-Nellore.

R. Bras. Zootec., v.33, n.4, p.858-869, 2004 
considerando-se os genótipos dos genes CSN3, GHe LGB de bovinos dos grupos genéticos CN, AN e SN.

Os valores das estimativas dos parâmetros $A, k$ e $m$, obtidos pelo modelo Logístico, foram adequados, com exceção das estimativas obtidas para os genótipos LV (GH) e AA (LGB) do grupo genético CN, cujas estimativas dos erros-padrão do parâmetro $A$ foram altas e de magnitude média, respectivamente, e as do parâmetro $k$ foram altas para os dois polimorfismos genéticos. O número limitado de informações dessas duas classes de genótipos pode ter sido determinante na não constatação de efeito significativo dos genótipos sobre a curva de crescimento.

Considerando-se os parâmetros $A$ e $k$, o genótipo AA para CSN3 apresentou valores superiores para o parâmetro $k$ em relação ao genótipo $\mathrm{AB}$ nos três grupos genéticos. $O$ tamanho à maturidade $(A)$ dos animais do genótipo AA apresentou pequena diferença em relação ao genótipo $\mathrm{AB}$ nos grupos genéticos $\mathrm{CN}, \mathrm{AN}$ e SN.

Para o polimorfismo do GH no grupo genético AN, a curva que descreve o crescimento dos animais do genótipo LL mostrou-se mais adequada, do ponto de vista de produção de bovinos de corte, apesar de apresentar taxa de maturação menor que o genótipo
LV. Entretanto, houve inversão dessa tendência no grupo genético SN. O mesmo ocorreu para o LGB, em que os genótipos $\mathrm{AA}$ e $\mathrm{AB}$ mostraram estimativas do parâmetro $k$ superiores em relação ao genótipo BB no grupo genético $A N$, enquanto o genótipo $A B$ apresentou estimativa de $k$ inferior em relação ao genótipo $\mathrm{BB}$, no grupo genético $\mathrm{SN}$.

Existem evidências de que os genes CSN3 e LGB tenham importante relação entre si (Bovenhuis et al., 1992). Os resultados encontrados na literatura com relação à associação de marcadores com características produtivas são conflitantes. Por exemplo, o alelo A do gene CSN3 foi associado à maior produção de leite por Bovenhuis et al. (1992) e Moody et al. (1996), enquanto Lin et al. (1989) e Cowan et al.(1991) observaram que o alelo B, desse mesmo gene, estava associado ao aumento de produção de leite. Estudos anteriores não detectaram diferenças dos efeitos dos genes CSN3 e LGB sobre características quantitativas. O genótipo LL do gene GH foi associado ao maior ganho de peso por Unanian et al. (2000), em animais da raça Nelore, enquanto Moody et al. (1996) verificaram que o alelo V estava associado ao maior ganho de peso no período do

Tabela 4 - Soma de quadrados do resíduo (SQR), graus de liberdade do resíduo (GLR), quadrado médio do erro (QME), dos modelos Completo e Reduzido, número dos conjuntos de parâmetros estimados (NP) e coeficiente de determinação $\left(R^{2}\right)$ do modelo Completo, valor observado de $F\left(F_{\text {obs }}\right)$ e probabilidade do valor observado de $F($ Prob $>F)$, para bovinos de três grupos genéticos

Table 4 - Residual sum of square (RSS), residual degrees of freedom (RDF), error mean square (EMS), of the Full and Reduced models, number of estimated parameters set to Full model $(P N)$, coefficient of determination $\left(R^{2}\right)$ of the Full model, observed $F$ value $\left(F_{o b s}\right)$ and probability of the observed $F$ value (Prob $\left.>F\right)$, of three genetic groups

\begin{tabular}{|c|c|c|c|c|c|c|c|c|c|c|}
\hline \multicolumn{3}{|c|}{$\begin{array}{l}\text { Grupo genético } \\
\text { Genetic group }^{1}\end{array}$} & \multicolumn{3}{|c|}{$\begin{array}{l}\text { Modelo completo } \\
\text { Full model }\end{array}$} & \multicolumn{2}{|c|}{$\begin{array}{l}\text { Modelo reduzido } \\
\text { Reduced model }\end{array}$} & \multirow[b]{2}{*}{$\begin{array}{l}\mathrm{R}^{2}(\%) \\
R^{2}(\%)\end{array}$} & \multirow[b]{2}{*}{$\begin{array}{l}\mathrm{F}_{\text {obs }} \\
F_{\text {obs }}\end{array}$} & \multirow[b]{2}{*}{$\begin{array}{l}\text { Prob }>F \\
\text { Prob }>F\end{array}$} \\
\hline & $\begin{array}{l}\text { Gene }^{2} \\
\text { Gene }^{2}\end{array}$ & $\begin{array}{l}\mathrm{NP} \\
P N\end{array}$ & $\begin{array}{l}\text { SQR } \\
R S S\end{array}$ & $\begin{array}{l}\text { GLR } \\
R D F\end{array}$ & $\begin{array}{l}\text { QME } \\
\text { EMS }\end{array}$ & $\begin{array}{l}\text { SQR } \\
R S S\end{array}$ & $\begin{array}{l}\text { GLR } \\
R D F\end{array}$ & & & \\
\hline \multirow{4}{*}{$\mathrm{CN}$} & CSN3 & 14 & 496.071 & 742 & 668,6 & 525.468 & 760 & 94,8 & 2,443 & 0,0007 \\
\hline & $\mathrm{GH}$ & 11 & 519.239 & 751 & 691.4 & 525.468 & 760 & 94,6 & 1,001 & 0,4375 \\
\hline & LGB & 20 & 490.756 & 724 & 677,8 & 525.468 & 760 & 94,8 & 1,423 & 0,0536 \\
\hline & CSN3 & 16 & 462.736 & 748 & 618,6 & 495.993 & 772 & 95,7 & 2,240 & 0,0006 \\
\hline \multirow[t]{3}{*}{ AN } & $\mathrm{GH}$ & 13 & 469.505 & 757 & 620,2 & 495.993 & 772 & 95,6 & 2,847 & 0,0002 \\
\hline & LGB & 21 & 455.017 & 733 & 620,8 & 495.993 & 772 & 95,8 & 1,692 & 0,0059 \\
\hline & CSN3 & 14 & 358.920 & 603 & 595,2 & 384.921 & 621 & 96,2 & 2,413 & 0,0009 \\
\hline \multirow[t]{2}{*}{ SN } & $\mathrm{GH}$ & 14 & 359.053 & 603 & 595,4 & 384.921 & 621 & 96,1 & 2,433 & 0,0008 \\
\hline & LGB & 16 & 324.021 & 597 & 542,7 & 384.921 & 621 & 96,6 & 4,675 & $<0,0001$ \\
\hline
\end{tabular}

R. Bras. Zootec., v.33, n.4, p.858-869, 2004 
nascimento ao desmame, em bovinos da raça Hereford. Estas contradições podem ser explicadas por diferenças no desequilíbrio de ligação entre marcadores e QTL (“Quantitative Trait Locus”) nas diferentes populações estudadas. Além disso, diferenças na base genética dessas populações também podem influenciar o efeito dos QTL (Moody et al., 1996).

Na Figura 2, estão representadas as curvas do peso (kg) em função da idade, ajustadas pelo modelo Logístico, para os genótipos dos genes da kappacaseína-HinfI (CSN3), do hormônio do crescimentoAluI (GH) e da $\beta$-lactoglobulina-HaeIII (LGB) dos grupos genéticos $1 \frac{1}{2}$ Canchim-Nelore (CN), $1 / 2$ AngusNelore (AN) e $1 / 2$ Simental-Nelore (SN).

Observa-se, por meio das estimativas de parâmetros da função Logística (Tabelas 4 e 5) e também pelo formato da curva (Figura 2), que o crescimento corporal nos três grupos genéticos (CN, AN e SN) foi influenciado pelos genótipos dos genes CSN3, GH e LGB.
As maiores diferenças entre os genótipos para os genes CSN3, GH e LGB foram encontradas a partir dos 12-13 meses de idade, concordando com os resultados encontrados por Unanian et al. (2000), que, usando o modelo Von Bertallanffy para descrever o crescimento de animais Nelore, encontraram tendência de associação do ganho de peso com os polimorfismos GH-AluI e GH-MspI, a partir dos 12-13 meses de idade. Em estudos que consideraram apenas o peso ao nascimento, Borges (1997) e Taylor et al. (1998) não encontraram diferenças significativas entre os polimorfismos do GH sobre o PN.

Análises inadequadas podem negligenciar aspectos importantes no padrão de desenvolvimento dos animais. Portanto, é relevante considerar que os pesos obtidos ao longo da vida do animal são correlacionados entre si, que a variância no peso é crescente em função da idade e que o custo de obtenção das análises laboratoriais utilizadas para determinação de polimorfismos genéticos é elevado, limitando o tamanho amostral.

Tabela 5 - Estimativas dos parâmetros $(A, k$ e $m$ ) e respectivos erros-padrão (ep), obtidas pelo modelo Logístico e número de animais $(\mathrm{N})$ que atingiram a convergência, para os polimorfismos genéticos de animais de três grupos genéticos (GG)

Table 5 - Estimate parameter $(A, k$ and $m$ ) and their stander error (se) obtains by Logistic model and number of animals that reached the convergence (N), from the three genetic groups (GG)

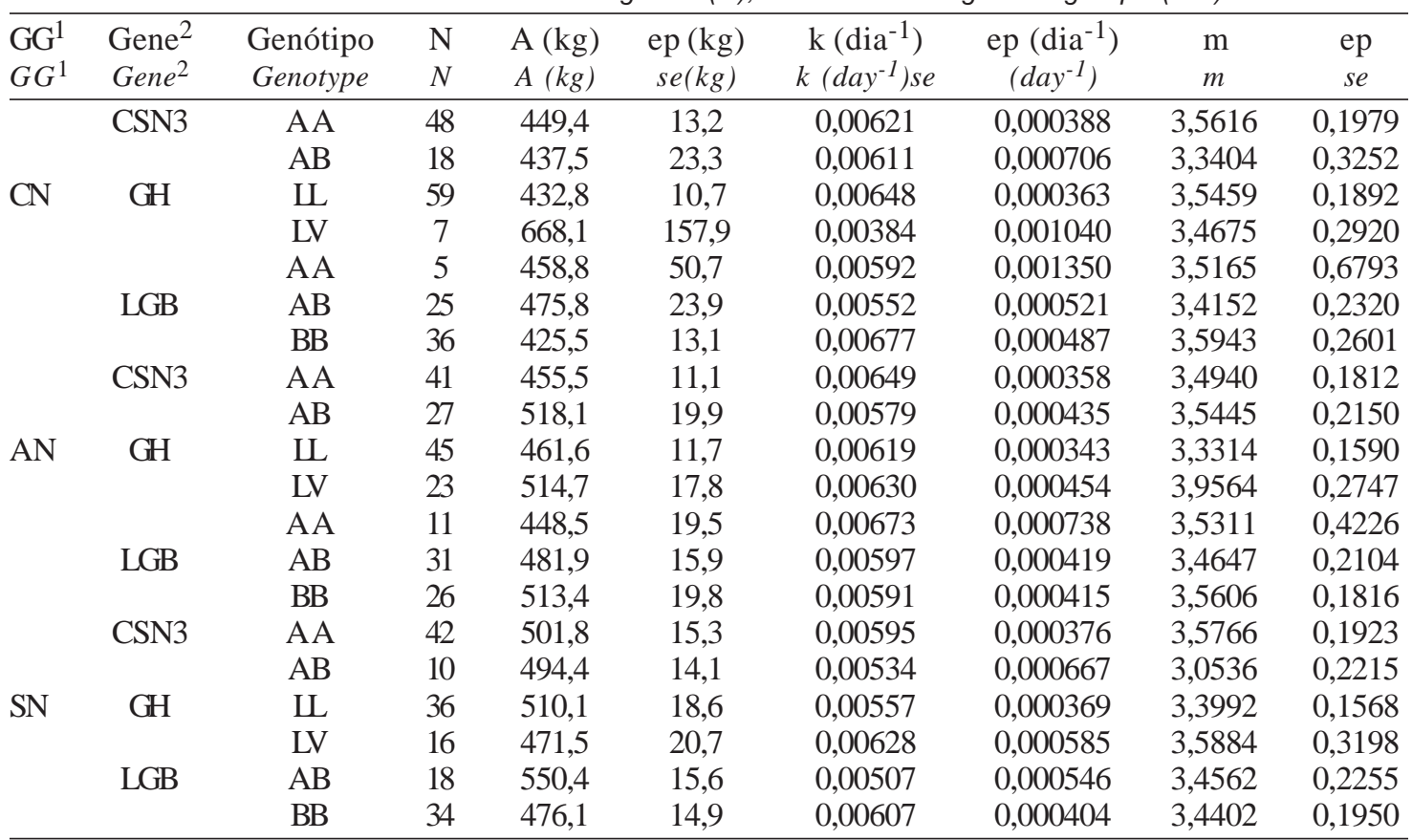

${ }^{1} \mathrm{CN}=1 / 2$ Canchim-Nelore; AN = 1/2Angus-Nelore; SN = 1/2Simental-Nelore.

${ }^{1} \mathrm{CN}=1 / 2$ Canchim-Nellore; $\mathrm{AN}=1 / 2$ Angus_Nellore; $S N=1 / 2$ Simmental-Nellore.

${ }^{2}$ CSN3 = gene da kappa-caseína-Hinfl; $\mathrm{GH}=$ gene do hormônio do crescimento-Alul; $L \mathrm{~GB}=$ gene da $\beta$-lactoglobulina-HaellI.

2 CSN3 = kappa-casein-Hinfl gene; $G H$ = growth hormone-Alul gene; $L G B=\beta$-lactoglobulin-Haelll gene. 
Nas condições em que foi realizado o presente estudo, é pertinente fazer algumas considerações com relação às análises realizadas com o objetivo de verificar possíveis associações entre polimorfismos genéticos e a curva de crescimento de bovinos cruzados.

Da mesma forma que ocorreu em análise anterior (Paz, 2002), na qual os parâmetros $A$, $k$ e $m$, estimados

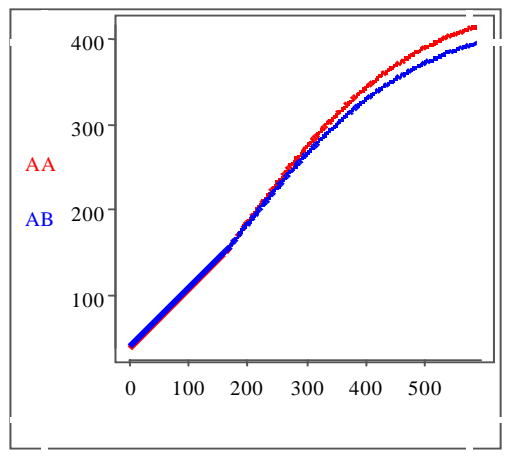

1/2Canchim-Nelore - CSN3 $1 / 2$ Canchim-Nellore-CSN3

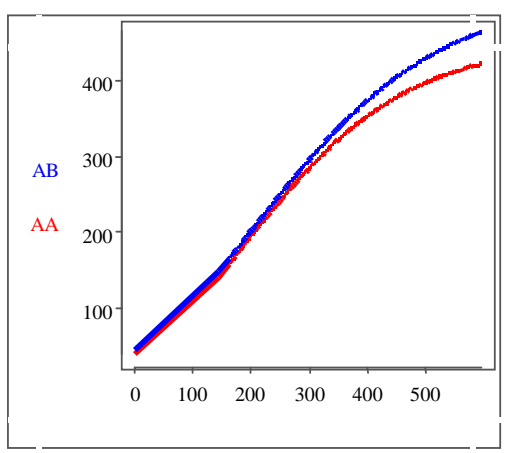

$1 / 2$ Angus-Nelore - CSN3 $1 / 2$ Angus-Nellore-CSN3

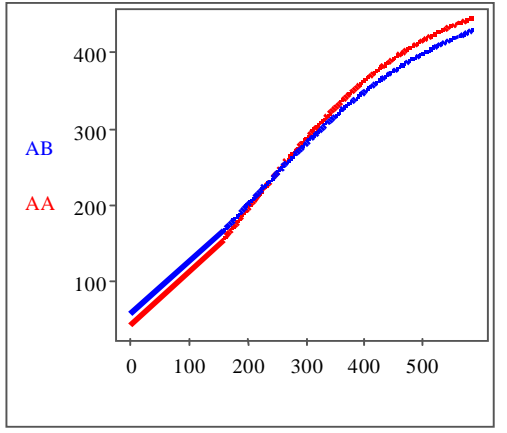

$1 / 2$ Simental-Nelore - CSN3 $1 / 2$ Simmental-Nellore - CSN3

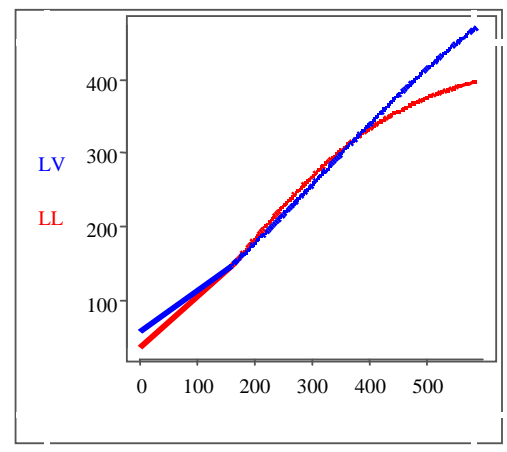

$1 / 2$ Canchim-Nelore - $\mathrm{GH}$

$1 / 2$ Canchim-Nellore - $\mathrm{GH}$

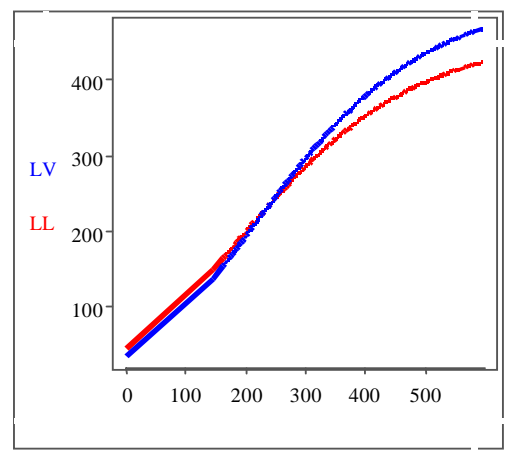

$1 / 2$ Angus-Nelore - $\mathrm{GH}$ $1 / 2$ Angus-Nellore-GH

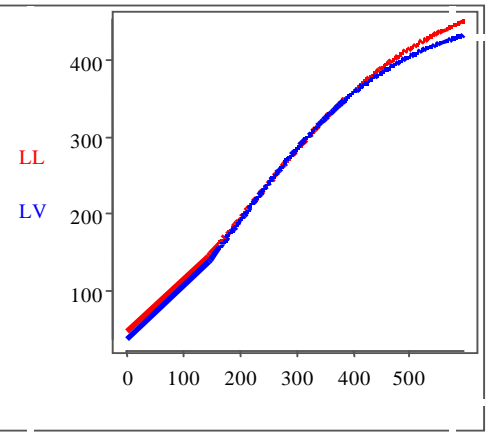

$1 / 2$ Simental-Nelore - GH $1 / 2$ Simmental-Nellore - GH

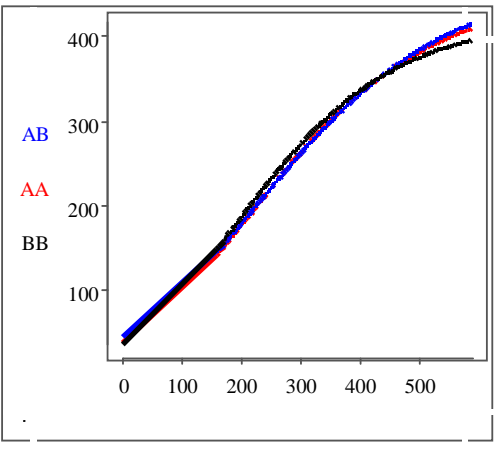

$1 / 2$ Canchim-Nelore - LGB $1 / 2$ Canchim-Nellore-LGB

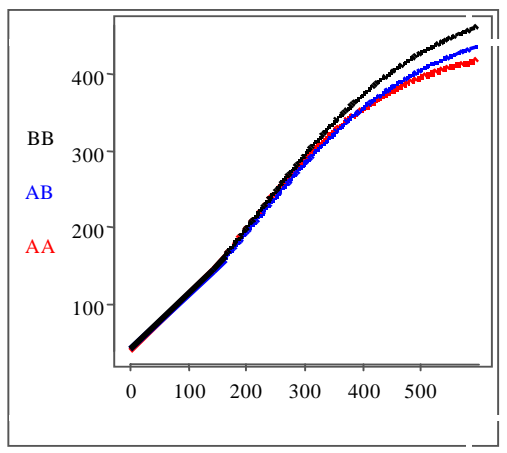

$1 / 2$ Angus-Nelore - LGB $1 / 2$ Angus-Nellore $-L G B$

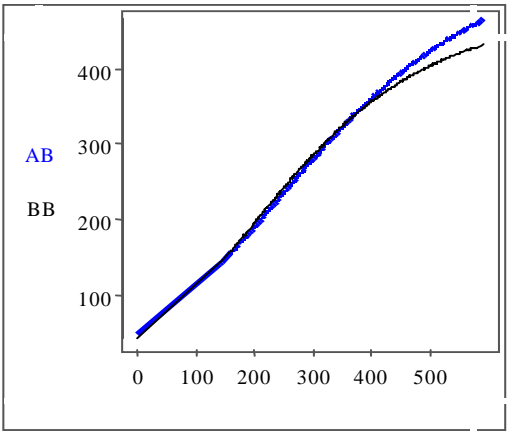

$1 / 2$ Simental-Nelore - LGB $1 / 2$ Simmental-Nellore - LGB

Figura 2 - Estimativa do peso $(\mathrm{kg})$ no eixo-y, em função da idade (dias) no eixo-x, ajustado pelo modelo Logístico para os genótipos dos genes da kappa-caseína-Hinfl (CSN3), do hormônio do crescimento-Alul (GH) e da $\beta$-lactoglobulina-HaellI (LGB), de animais de três grupos genéticos.

Figure 2 - Estimate of body weight $(\mathrm{kg})$ in the $y$-axis, by age (days) in the $x$-axis, adjusted by Logistic model for genotypes of the kappa-casein-Hinfl (CSN3), growth hormone-Alul (GH) e b-lactoglobulin-Haelll (LGB) genes, from the three genetic groups.

R. Bras. Zootec., v.33, n.4, p.858-869, 2004 
para cada animal, foram analisados por meio de modelos lineares, a fim de verificar o efeito dos polimorfismos genéticos sobre esses parâmetros, na presente análise, que considerou os parâmetros e os efeitos fixos de ambiente e de polimorfismo genético simultaneamente, pode-se admitir que os resultados foram prejudicados pelo reduzido número de informações, por fatores ambientais pouco controlados, além do fato de que os animais não apresentavam registros completos dos pesos ao longo de suas vidas produtivas. No entanto, os problemas associados à segunda abordagem de análise podem ter sido superados ou pelo menos minimizados, em razão de ter considerado o peso do animal ao longo de sua vida (estudo inédito), ou seja, a associação entre polimorfismos genéticos e características de crescimento por meio de ajuste de curvas de crescimento, estimando simultaneamente os parâmetros destas curvas e os efeitos destes polimorfismos. Esta abordagem proporcionou uma análise mais adequada que a primeira (Paz, 2002). Principalmente porque, na primeira abordagem, a pré-correção para os efeitos fixos de ambiente não proporcionou estimativas coerentes para os parâmetros das funções não-lineares e porque, na segunda abordagem, foi possível considerar os efeitos fixos (genótipo e grupos de contemporâneos) no modelo e estimar os parâmetros da função Logística, simultaneamente.

Entretanto, é relevante recomendar análises adicionais em populações maiores e com fatores ambientais mais controlados, uma vez que este experimento foi limitado pelo custo de obtenção destes polimorfismos, além de a metodologia ter sido aplicada a dados de associação entre polimorfismos genéticos e parâmetros da curva de crescimento animal pela primeira vez.

\section{Conclusões}

O presente trabalho pode ser considerado preliminar nos estudos de associação entre polimorfismos genéticos e a curva de crescimento de bovinos. A abordagem proposta mostrou-se adequada para descrever o crescimento animal e pode ser estendida a outras áreas científicas que utilizem dados de peso em função da idade com o propósito de estudar outros fatores que influenciem os parâmetros da curva de crescimento, além dos polimorfismos genéticos. Esta nova abordagem de análise é mais abrangente e adequada que a usualmente empregada em estudos de crescimento, na qual os parâmetros estimados para a curva de cada animal são analisados por meio de modelos lineares.

A possível aplicação dos resultados deste estudo em programa de seleção assistida por marcadores (MAS) ainda é prematura. Entretanto, evidências de que os polimorfismos dos genes da kappa-caseínaHinfI, do hormônio do crescimento-AluI e da $\beta$-lactoglobulina-HaeIII influenciem a curva de crescimento dos bovinos $1 / 2$ Canchim-Nelore, $1 / 2$ AngusNelore e $1 / 2$ Simental-Nelore sugerem que, no futuro, os genótipos destes genes poderão ser usados em programas de seleção assistida por marcadores.

\section{Literatura Citada}

ARKINS, S.; DANTZER, R.; KELLEY, K.W. Somatolactogens, somatomedins, and immunity. Journal of Dairy Science, v.76, p.2437-2442, 1993.

BARENDSE, W.; VAIMAN, D.; KEMP, S.J. et al. A mediumdensity genetic linkage map of the bovine genome. Mammalian Genome, v.8, p.21-28, 1997.

BORGES, M. Marcadores moleculares seus efeitos sobre características quantitativas de bovinos de corte. Uberlândia: Universidade Federal de Uberlândia, 1997. 119p. Dissertação (Mestrado) - Universidade Federal de Uberlândia, 1997.

BOVENHUIS, H.; Van ARENDONK, J.A.M.; KORVER, S. Associations between milk protein polymorphisms and milk production traits. Journal of Dairy Science, v.75, n.9, p.2549-2599, 1992.

COWAN, C.M.; DENTINE, M.R.; COYLE, T. Chromosome substitution effects associated with $\kappa$-casein and $\beta$-lactoglobulin in Holstein Cattle. Journal of Dairy Science, v.75, n.4, p.1097-1104, 1991.

DISTASIO, L.; SARTORE, S.; ALBERA, A. Lack of association of GH1 and POU1F1 gene variants with meat production traits in Piemontese cattle. Animal Genetics, v.33, p.61-64, 2002.

ELIAS, A.M. Análise de curvas de crescimento de vacas das raças Nelore, Guzerá e Gir. Piracicaba: Escola Superior de Agricultura "Luiz de Queiroz", 1998. 128p. Dissertação (Mestrado em Ciência Animal e Pastagens) - Escola Superior de Agricultura "Luiz de Queiroz”, 1998.

GLUCKMAN, P.D.; BREIER, B.G.; DAVIS, S.R. Physiology of somatotropic axis with particular reference to the ruminant. Journal of Dairy Science, v.70, p.442-466, 1987.

GOONEWARDENE, L.A.; BERG, R.T.; HARDIN, R.T. A growth study of beef cattle. Canadian Journal of Animal Science, v.61, p.1041-1048, 1981.

HINES, H.C.; ZIKAKIS, J.P.; HAENLEIN, C.A. et al. Linkage relationships among loci of polymorphism in blood and milk of cattle. Journal of Dairy Science, v.64, n.1, p.71-76, 1981.

HOJ, S.; FREDHOLM, M.; LARSEN, N.J. et al. Growth hormone gene polymorphism associated with selection or milk fat production in lines of cattle. Animal Genetics, v.24, p.91-96, 1993. 
KIRKPATRIC, B.W. Detection of a three-allele single strand conformation polymorphism (SSCP) in the fourth intron of the bovine growth hormone gene. Animal Genetics, v.23, p.179-181, 1992.

LIN, C.Y.; McALLISTER, J.; NG-KWAI-HANG, K.F. et al. Association of milk protein with growth and reproductive performance of dairy heifers. Journal of Dairy Science, v.70, p.29-39, 1987.

LIN, C.Y.; McALLISTER, J.; NG-KWAI-HANG, K.F. et al. Relationships of milk protein types to lifetime performance. Journal of Dairy Science, v.72, n.11, p.3085-3090, 1989.

LIN, C.Y.; SABOUR, M.P.; LEE, A.J. Direct typing of milk proteins as an aid genetic improvement of dairy bulls and cows: a review. Animal Breeding Abstracts, v.60, p.1-10, 1992.

LUCY, M.C.; HAUSER, S.D.; EPPARD, P.J. et al. Genetic polymorphism within the bovine somatotropin (bST) gene detected by polymerase chain reaction and endonuclease digestion. Journal of Dairy Science, v.74, suppl.1, p.284, 1991.

MEDRANO, J.F.; AGUILAR-CORDOVA, E. Genotyping of bovine kappa-casein loci following DNA sequence amplification. Bio/Technology, v.8, p.144-146, 1990a.

MEDRANO, J.F.; AGUILAR-CORDOVA. E. Polymerase chain reaction amplification of bovine $\beta$-lactoglobulin genomic sequences and identification de genetic variants by RFLP analysis. Animal Biotechnology, v.1, p.73-77, 1990b.

MOODY, D.E.; POMP, D.; NEWMAN, S.; MACNEIL, M.D. Characterization of DNA polymorphisms in three populations of Hereford cattle and their associations with growth and maternal EPD in line 1 Herefords. Journal of Animal Science, v.74, p.1784-1793, 1996.

NELDER, J.A. The fitting of a generalization of the logistic curve. Biometrics, v.17, p.89-110, 1961.

NG-KWAI-HANG, K.F.; HAYES, J.F.; MOXLEY, J.E. et al. Association of genetic variants of casein and milk serum protein with milk, fat and protein production by dairy cattle. Journal of Dairy Science, v.67, p.835-840, 1984.

PAZ, C.C.P. Associação entre polimorfismos genéticos e parâmetros da curva de crescimento em bovinos de corte. Piracicaba: Escola Superior de Agricultura "Luiz de Queiroz”, 2002. 106p. Tese (Doutorado em Ciência Animal e Pastagens) - Escola Superior de Agricultura “Luiz de Queiroz”, 2002.

ROCHA, J.L.; BAKER, J.F.; WOMACK, J.E. et al. Statistical associations between restriction fragment length polymorphisms and quantitative traits in beef cattle. Journal of Animal Science, v.70, p.3360-3370, 1992.

RON, M.; YOFFE, O.; MEDARANO, J.F. et al. Determination of effects of milk protein genotype on production traits of Israeli Holsteins. Journal of Dairy Science, v.77, p.1106-1113, 1994.
SARTORI, S.; DI STASIO, L. Analisi genetica del locus GH (ormone della crescita) nella razza bovina Piemontesa. In: CONVEGNO SOCIETÀ ITALIANA DELLE SCIENZE VETERINARIE LIV, 54., 2000. Proceedings... s.l.: s.ed., 2000. p. 411-412.

STATISTICAL ANALYSES SYSTEM - SAS. SAS/STAT 2001: user's guide: statistics version 8.2, CD-ROM. Cary, 2001.

SCHABENBERGER, O. Nonlinear regression with the SAS system. http://www.cas.vt.edu/schabenb/SASNlin.htm. (14 nov. 2001).

SCHLEE, P.; GRAML, R.; ROTTMANNN,O. et al. Influence of growth-hormone genotypes on breeding values Simmental bulls. Journal of Animal Breeding and Genetics, v.111, p.253-256,1994a.

SCHLEE, P.; GRAML, R.; SCHALLEMBERGER, E. et al. Growth hormone AND insulin-like growth factor-I concentrations in bull of various growth hormone genotypes. Theoretical and Applied Genetics, v.88, p.497-500, 1994b.

TAMBASCO, D.D.; PAZ, C.C.P.; TAMBASCO-STUDART, $M$. et al. Candidate genes for growth traits in beef cattle crosses Bos taurus $x$ Bos indicus. Journal of Animal Breeding and Genetics, v.120, n.1, p.51-56, 2003.

TAYLOR, J.F.; COUTINHO, L.L.; HERRING, K.L. et al. Candidate gene analysis of GH1 for effects on growth and carcass composition of cattle. Animal Genetics, v.29, p.194-201, 1998.

UNANIAN, M.M.; BARRETO, C.C.; FREITAS, A.R. et al. Associação do polimorfismo do gene do hormônio do crescimento com a caraterística peso em bovinos da raça Nelore. Revista Brasileira de Zootecnia, v.29, n.5, p.13801386, 2000.

YAO, J.; AGGREY, S.E.; ZADWORNY, D. et al. Sequence variations inthe bovine growth hormone gene characterized by single-strand conformation polymorphism (SSCP) analysis and their association with milk production traits in Holsteins. Genetics, v.144, p.1809-1816, 1996.

ZHANG, H.M.; BROWN, D.R.; DeNISE, S.K. et al. Rapid communication: polymerase chain reaction-restriction fragment length polymorphism analysis of the bovine somatotropin gene. Journal of Animal Science, v.71,n.8, p.2276, 1993.

Recebido em: 21/10/02 Aceito em: 12/11/03 